\title{
OBTAINING OF LOCALLY OPTIMAL SOLUTIONS BY COMBINING PROPERTIES OF MIXTURES FOR FOUNDRY MANUFACTURE
}

\author{
Vadim Dotsenko \\ Department of Foundry technologies \\ Odessa National Polytechnic University \\ 1 Shevchenko ave., Odessa, Ukraine, 65044 \\ e.e.kaschenko@opu.ua \\ Viktoria Boichuk \\ Department of Foundry Production \\ National Technical University «Kharkiv Polytechnic Institute» \\ 2 Kyrpychova str., Kharkiv, Ukraine, 61002 \\ litvo11@kpi.kharkov.ua \\ Vadym Fedorenko \\ Department of Foundry Production \\ National Technical University «Kharkiv Polytechnic Institute» \\ 2 Kyrpychova str., Kharkiv, Ukraine, 61002 \\ litvol1@kpi.kharkov.ua \\ Yevhenii Tsybulskyi \\ Department of Foundry Production \\ National Technical University «Kharkiv Polytechnic Institute» \\ 2 Kyrpychova str., Kharkiv, Ukraine, 61002 \\ litvol1@kpi.kharkov.ua
}

\begin{abstract}
The aim of research is establishment of the relationship between the various properties of the mixture with liquid glass and hardener for the foundry industry - survivability, compressive strength and crumbling. Such an interrelation in the form of an adequate functional dependence makes it possible to assess the quality of the mixture for its compliance with the specified requirements, without resorting to additional laboratory measurements. It is very important to evaluate its suitability for the manufacture of rods, in particular, to meet the stringent requirements of production. Using the combined procedure of active and passive experiments, a regression equation was obtained describing the dependence of the mixture survivability on compressive strength and crumbling. It has been established that compressive strength is a more significant factor influencing survivability compared to crumbling, and it is almost 3 times $\left(a_{1}=0.36>a_{2}=0.13\right)$. Analysis of the resulting regression equation shows that both of these factors have a positive effect on the survivability of the mixture - with an increase in compressive strength and crumbling, the survivability increases. In part, this conclusion requires confirmation in relation to crumbling, since the fact of a positive effect on survivability may be in doubt.

By applying the procedure of comb analysis to the obtained regression equation, in order to describe the response surface, locally optimal solutions are established in the form of a ridge line. This line represents the optimal combination of compressive strength and shedding in the sense of ensuring the maximum survivability of the mixture. The corresponding ratios can be used as a nomogram, which allows to evaluate the ratios of the desired properties of the mixture, if it is fundamentally important to assess its quality by a set of properties.
\end{abstract}

Keywords: foundry, mixture with liquid glass and hardener, regression equation, ridge analysis.

\section{Introduction}

Accumulated information in the form of primary experimental data and expert opinion from a number of experts in the field of foundry requires formalization. Its goal is to obtain an adequate mathematical description of the studied processes for further use in SCADA systems or decision support systems, where automation is difficult. There are no exceptions to the task of 
finding the optimal technological solutions in the mixing preparation for one-time casting molds. The quality of the surface of castings, its dimensional and geometrical accuracy depends on the quality of the mixtures.

A study of the mutual influence of the properties of mixtures, as a binder in which liquid glass is used, as well as a hardener is conducted. This study is carried out within the framework of applied topics "Development and implementation of materials for the manufacture of molds and cores in order to reduce the cost of their manufacture in a production environment" [1-3]. This study is based on the results of [4] and is a continuation of this topic, developed in [5, 6]. Its relevance is justified by the fact that in production conditions it is necessary to ensure high performance of several properties of mixtures at once, which affect the quality of casting molds. However, often some of them are in conflict - an improvement of one leads to the deterioration of the other. It is necessary either to give priority to one of the properties, or to seek a compromise solution. In this regard, it is practically important to know the real possibilities in ensuring the specified properties, for which it is necessary to know their mutual influence. For this, it is necessary to have an adequate mathematical model reflecting the functional connection between different properties.

\section{Materials and Methods}

The ranges of variation of the input variables are chosen as follows: $\mathrm{x}_{1}$-liquid glass, mass $\mathrm{p}$ : 3-4, $\mathrm{x}_{2}$ - hardener, mass p: 0.3-0.4. Resistance variables $\left(\mathrm{y}_{1}\right)$, compressive strength after 24 hours $\left(y_{2}\right)$, crumbling after 24 hours of hardening $\left(y_{3}\right)$ are chosen as output variables. The experimental technique, conditions and requirements for the characteristics of the mixture are described in detail in [4-6]. The objective of this research is establishment of the functional dependence of the form $\mathrm{y}_{1}=\varphi\left(\mathrm{y}_{2}, \mathrm{y}_{3}\right)$, which allows predicting the main output characteristic - survivability - according to two other characteristics - compressive strength after 24 hours and crumbling after 24 hours of hardening. If such a relationship is adequate, it allows to evaluate the quality of the mixture to meet its specified requirements, without resorting to additional laboratory measurements. It is very important to evaluate its suitability for the manufacture of rods, in particular, to meet such stringent requirements:

- rods made of this mixture must have strength that allows for turning, transport and painting 3 hours after production, equal to $2-2.5 \mathrm{MPa}$;

- mixtures should not be weakened during long-term storage and have a strength of at least $4 \mathrm{MPa}$ (after 24 hours) in the manufacture of large rods of 3-4 classes of complexity;

- crumbling of mixtures should not exceed $0.2 \%$.

To solve this problem, let's use the least squares method [7] and a ridge analysis of the obtained regression equation [8].

The estimates of the coefficients of the mathematical model in the form of the regression equation $\mathrm{y}_{1}=\varphi\left(\mathrm{y}_{2}, \mathrm{y}_{3}\right)$ are calculated by the formula:

$$
\mathrm{A}=\left(\mathrm{F}^{\mathrm{T}} \mathrm{F}\right)^{-1} \mathrm{~F}^{\mathrm{T}} \mathrm{Y}=\mathrm{CF} \mathrm{F}^{\mathrm{T}} \mathrm{Y}
$$

where $\mathrm{F}$ - the experiment plan matrix, $\mathrm{F}^{\mathrm{T}}$ - the transposed matrix of the experiment plan, $\mathrm{C}=\left(\mathrm{F}^{\mathrm{T}} \mathrm{F}\right)^{-1}-$ the dispersion matrix, $\mathrm{Y}$ - the mixture quality matrix $\left(\mathrm{y}_{1}\right), \mathrm{A}-$ the coefficient matrix. The matrix of the experiment plan in this case included the values of the input variables $\mathrm{y}_{2}$ and $\mathrm{y}_{3}$.

For the analysis of the response surface described by the obtained regression equation, let's use a parametric description of the form

$$
\left\{\begin{array}{l}
x^{*}(\lambda)=(\lambda I-A)^{-1} a, \\
r(\lambda)=\sqrt{x^{* \prime} x^{*}} \\
y^{*}(\lambda)=a_{0}+2 a^{\prime} x^{*}+x^{* \prime} A x^{*}
\end{array}\right.
$$

where $\mathrm{a}_{0}$ - the initial coefficient of the regression equation, $\mathrm{a}, \mathrm{A}-$ the matrices of linear and nonlinear coefficients of the regression equation,,$\lambda$ - the eigenvalues of the matrix $A, x^{*}(\lambda)$ - the optimal 
values of the input variables, $r(\lambda)$-the radius of the conditional cylinder describing constraints, $y^{*}(\lambda)$ - the optimal values of the output variable.

\section{Experimental procedures}

Table 1 shows the matrix of the orthogonal central composition plan (OCCP) for two variable factors (the content of liquid glass and the hardener) and the results of industrial studies of the properties of mixtures with corresponding sets of values of these factors.

Table 1

OCCP matrix and the results of industrial studies of the properties of mixtures

\begin{tabular}{|c|c|c|c|c|c|c|c|c|c|c|}
\hline \multirow{2}{*}{\multicolumn{2}{|c|}{$\begin{array}{c}\text { The range of } \\
\text { factors }\end{array}$}} & \multicolumn{6}{|c|}{ Planning matrix } & \multicolumn{3}{|c|}{ Properties of the mixture } \\
\hline & & \multicolumn{6}{|c|}{ Normalized and natural values of input variables, mass p. } & \multirow{2}{*}{$\begin{array}{l}\text { Surviv- } \\
\text { ability, } \\
\text { min. }\end{array}$} & \multirow{2}{*}{$\begin{array}{l}\text { Compressive } \\
\text { strength, MPa, } \\
\text { after } 24 \mathrm{~h} .\end{array}$} & \multirow[t]{2}{*}{$\begin{array}{l}\text { Crum- } \\
\text { bling, \% }\end{array}$} \\
\hline Mai & & 0 & 3,5 & 0,35 & \multirow{2}{*}{\multicolumn{3}{|c|}{$\begin{array}{l}\text { Quadratic values of factors and } \\
\text { the effect of the mutual action } \\
\text { of factors on the properties of } \\
\text { the mixture }\end{array}$}} & & & \\
\hline \multicolumn{2}{|c|}{ Variation interval } & +1 & 0,5 & 0,05 & & & & \multicolumn{3}{|c|}{$\begin{array}{l}\text { Output variables }- \text { mixture quality } \\
\text { indicators }\end{array}$} \\
\hline \multicolumn{2}{|c|}{ Lower level } & -1 & 3,0 & 0,3 & & & & & & \\
\hline \multicolumn{2}{|c|}{ designations } & $\mathrm{x}_{0}$ & $\mathrm{x}_{1}$ & $\mathrm{x}_{2}$ & $\left(\mathrm{y}_{2}^{2}-\beta\right)$ & $\left(y_{3}^{2}-\beta\right)$ & $\mathrm{x}_{1} \mathrm{x}_{2}$ & $\mathrm{y}_{1}$ & $\mathrm{y}_{2}$ & $\mathrm{y}_{3}$ \\
\hline \multirow{9}{*}{$\begin{array}{l}\text { Exper- } \\
\text { iment } \\
\text { number }\end{array}$} & 1 & +1 & -1 & -1 & 0,33 & 0,33 & +1 & 14 & 4,45 & 0,15 \\
\hline & 2 & +1 & +1 & -1 & 0,33 & 0,33 & -1 & 15 & 6,43 & 0,07 \\
\hline & 3 & +1 & -1 & +1 & 0,33 & 0,33 & +1 & 14 & 3,23 & 0,24 \\
\hline & 4 & +1 & +1 & +1 & 0,33 & 0,33 & -1 & 15 & 5,43 & 0,05 \\
\hline & 5 & +1 & 0 & 0 & $-0,67$ & $-0,67$ & 0 & 14 & 5,53 & 0,06 \\
\hline & 6 & +1 & 0 & +1 & $-0,67$ & 0,33 & 0 & 15 & 5,09 & 0,11 \\
\hline & 7 & +1 & 0 & -1 & $-0,67$ & 0,33 & 0 & 14 & 4,43 & 0,06 \\
\hline & 8 & +1 & +1 & 0 & 0,33 & $-0,67$ & 0 & 15 & 6,0 & 0,04 \\
\hline & 9 & +1 & -1 & 0 & 0,33 & $-0,67$ & 0 & 14,5 & 3,76 & 0,19 \\
\hline
\end{tabular}

From Table 1, describing the experiment plan, it follows that each output variable is estimated on the basis of an orthogonal plan. This means that the estimates of the coefficients of the regression equations for each output variable are the most accurate. However, if investigate the dependence of any one output variable on the others, the conditions of orthogonality are not satisfied. Therefore, it is necessary to build a regression equation according to the available plan of a passive experiment. In this case, estimates of the coefficients of the corresponding regression equation are calculated based on the matrix equation (1), which implements the least squares method.

\section{Results}

Table 2 shows the results of calculations of the matrix of coefficients in the parametric description (2) and the calculated values of the poles, allowing to construct the lines of the ridges. These lines describe the sets of suboptimal values of the output variable obtained at the intersection of the response surface $\mathrm{y}_{1}=\varphi\left(\mathrm{y}_{2}, \mathrm{y}_{3}\right)$ and the surface $\mathrm{r}(\lambda)$, the analytical description of which has the form of the second equation in (2). 
Table 2

The coefficients of the mathematical model in the parametric description (2) and the calculated values of the poles

\begin{tabular}{|c|c|c|c|c|}
\hline \multirow[b]{2}{*}{$a_{0}$} & \multirow[b]{2}{*}{ a } & \multirow{2}{*}{$\mathbf{A}$} & \multicolumn{2}{|c|}{ Poles } \\
\hline & & & $\lambda_{1}$ & $\lambda_{2}$ \\
\hline 14,51564 & $\left(\begin{array}{l}0,358207 \\
0,127599\end{array}\right)$ & $\left(\begin{array}{cc}0 & -0,0309 \\
-0,0309 & 0\end{array}\right)$ & $-0,0309$ & 0,0309 \\
\hline
\end{tabular}

Fig. 1, 2 shows the solutions obtained in the form of two parametric descriptions: $r=r(\lambda)$ and $\mathrm{y}_{1}=\mathrm{y}_{1}^{*}(\lambda)$, respectively.

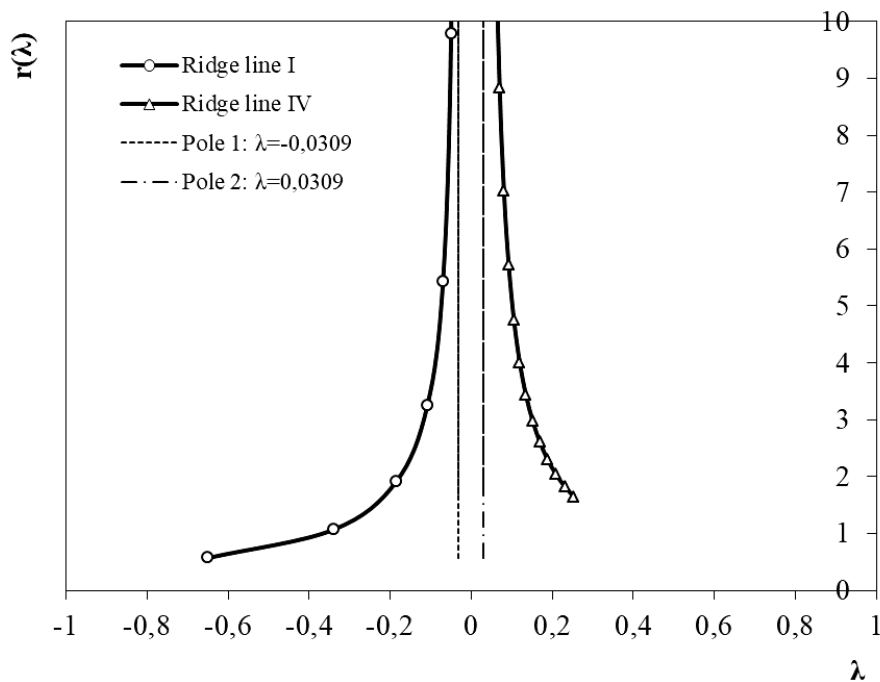

Fig. 1. Parametric type of constraints $r=r(\lambda)$

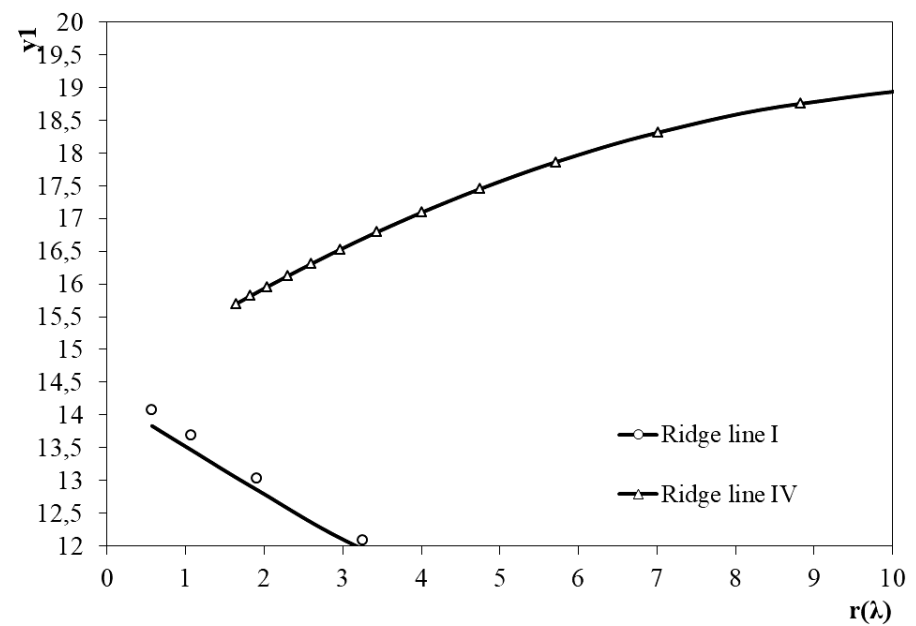

Fig. 2. The lines of the ridges $y_{1}=y_{1} *(\lambda)$, describing locally optimal (suboptimal) solutions

Fig. 3 shows a nomogram describing the permissible set of pairs $\left(\mathrm{y}_{2}, \mathrm{y}_{3}\right)$, which provide the required values for the survivability of the mixture. This set corresponds to locally optimal solutions.

From Fig. 3, it can be seen that both ridge lines go beyond the limits of the planning area; therefore, only parts of them can be used to search for locally optimal solutions. Namely, those that are inside this area. In this case, as follows from Fig. 2, the survivability maxima are determined 
on the ridge line IV, which, by the variable $y_{2}$, is completely outside the zone of the experiment plan. Given the linearity of the resulting regression equation, it can be assumed that the theoretical achievement of high survivability rates (15.5 minutes or more) is possible.

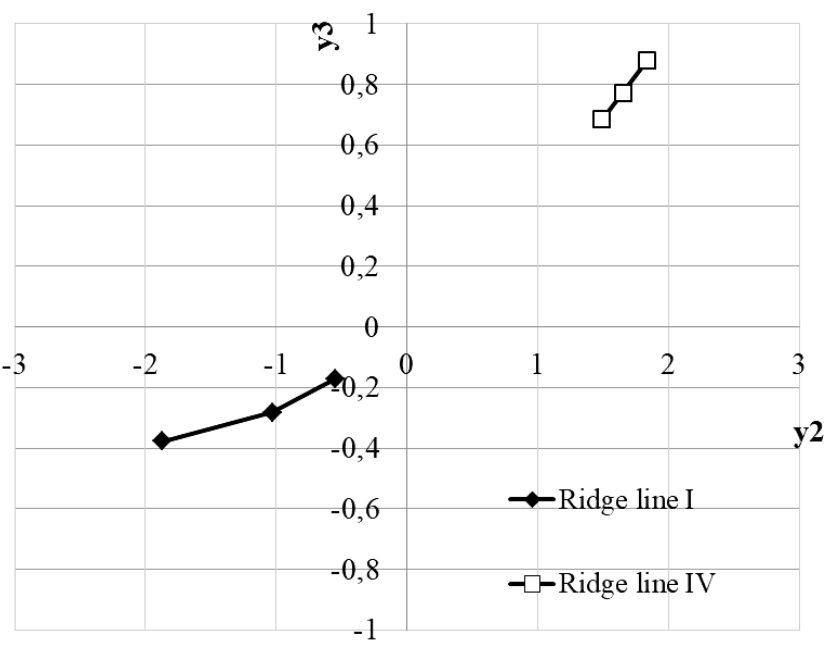

Fig. 3. Nomogram describing the permissible set of pairs $\left(\mathrm{y}_{2}, \mathrm{y}_{3}\right)$, which provide the required values of the survivability of the mixture (given in normalized form)

\section{Discussion}

As follows from the obtained results of determining the suboptimal values of the output variable (Fig. 2), in the considered area limited by the experimental plan given in Table 1, there is only one line of ridges I. However, the maximum values of the output variable are not provided on it. Consequently, the ridge line I allows to determine the allowable set of pairs $\left(\mathrm{y}_{2}, \mathrm{y}_{3}\right)$ at which the required values of the mixture survivability are provided in the range (1214) min. These pairs in the form of dependences $y_{3}=f\left(y_{2}\right)$ are shown in Fig. 3. This graphical dependence is a nomogram that allows to solve the inverse problem of synthesis of a mixture with a given set of properties. This is because this description is locally optimal. However, this result is not satisfactory if the vitality must be at least 14 minutes. In this case, a locally optimal solution should be sought on the ridge line IV. It can be seen (Fig. 2) that the maximum is reached near the boundary of the experimental design area $(\mathrm{r}=1.414$, which follows from the experimental design and the second equation in the parametric description (2)). This maximum is 15.5 minutes. It is especially important that, given the linearity of the regression equation, a prediction can be made outside the planning area. In this case, the theoretical values of the survivability of the mixture can be more than 15.5 minutes. However, this theoretical result must be verified experimentally.

The limitation of this study is due to the assumption that the distribution law $\mathrm{y}_{1}$ is normal. This assumption does not have a strict justification and is based on the availability of expert experience. In addition, the input variables chosen for the model $\mathrm{y}_{1}=\varphi\left(\mathrm{y}_{2}, \mathrm{y}_{3}\right)$ are in fact also output variables. That is, the requirement of independence of the output variables may also not be satisfied. Therefore, the development perspective of this research may be a fuzzy approach to modeling [9]. In particular, the considered input and output variables can be represented by fuzzy numbers. In this case, it is possible to solve the fuzzy regression analysis problem, after conducting the fuzzy clustering procedure [10]. In this case, the search for suboptimal solutions must take into account the presence of a two-level uncertainty - with respect to the modal value of $y_{1}$ and with respect to the compactness of the body of uncertainty.

The solutions obtained in the field of synthesis of mixtures with a given set of properties can stimulate global manufacturers of mixing equipment, for example [11-13]. A more complete list of potentially interested companies in the search for optimal solutions for the synthesis of mixtures for foundry can be found, for example, at source [14]. 


\section{Conclusions}

A regression equation is obtained that reflects the functional relationship between such properties of a mixture with liquid glass and a hardener - survivability, compressive strength, and crumbling. It has been established that compressive strength is a more significant factor influencing survivability compared to crumbling, and it is almost 3 times $\left(a_{1}=0,36>a_{2}=0,13\right)$. Both of these factors have a positive effect on the survivability of the mixture - with an increase in compressive strength and crumbling, the vitality increases. In part, this conclusion requires confirmation in relation to crumbling, since the fact of a positive effect on survivability may be in doubt.

The resulting suboptimal solutions in the form of a line of the comb $y_{3}=f\left(y_{2}\right)$ ) can be used as a nomogram, allowing to evaluate the ratios of the desired properties of the mixture, optimal in the chosen sense.

\section{References}

[1] Ponomarenko, O. I., Evtushenko, N. S., Berlizeva, T. V. (2011). Vliyanie zhidkih otverditeley s raznymi dobavkami na svoystva zhidkostekol'nyh smesey. Liteynoe proizvodstvo, 4, 21-24.

[2] Berlizeva, T. V., Ponomarenko, O. I., Karateev, A. M., Litvinov, D. A. (2013). Vliyanie furfuriloksipropilciklokarbonatov (FOPCK) s razlichnymi dobavkami na svoystva holodnotverdeyushchih smesey na zhidkom stekle. Kompressornoe i energeticheskoe mashinostroenie, 3, 26-29.

[3] Evtushenko, N. S., Shinskiy, O. I., Ponomarenko, O. I. (2013). Issledovanie svoystv regeneriruemyh smesey na osnove OFOS. Kompressornoe i energeticheskoe mashinostroenie, 4, 48-51.

[4] Kovalenko, B. P., Demin, D. A., Bozhko, A. B. (2006). Optimizaciya sostava holodnotverdeyushchih smesey (HTS) s propilenkarbonatom. Eastern-European Journal of Enterprise Technologies, 6, 59-61.

[5] Zinchenko, P. S., Aksenenko, M. P., Yovbak, A. V., Orendarchuk, Yu. V. (2016). Application of liquid glass mixtures with reduced content of liquide glass as a factor in improving the quality of machine-building castings. ScienceRise, 5 (2 (22)), 6-9. doi: https://doi.org/10.15587/2313-8416.2016.69836

[6] Orendarchuk, Y., Krasnoukhova, A., Achkasov, I., Barsuk, A., Holovko, V. (2016). Optimization of molding compounds for computer-cast parts of internal combustion engines. Bulletin of NTU "KhPI". Series: Mechanical-technological systems and complexes, 50 (1222), 117-121.

[7] Demin, D. (2013). Artificial orthogonalization in searching of optimal control of technological processes under uncertainty conditions. Eastern-European Journal of Enterprise Technologies, 5 (9 (65)), 45-53. Available at: http://journals.uran.ua/eejet/article/view/18452/16199

[8] Demin, D. (2017). Synthesis of optimal control of technological processes based on a multialternative parametric description of the final state. Eastern-European Journal of Enterprise Technologies, 3 (4 (87)), 51-63. doi: https://doi.org/10.15587/1729-4061.2017.105294

[9] Raskin, L. G., Seraya, O. V. (2008). Nechetkaya matematika. Kharkiv: Parus, 352.

[10] Demin, D. (2013). Mathematical modeling in the problem of selecting optimal control of obtaining alloys for machine parts in uncertainty conditions. Problemy mashinostroeniya, 16 (6), 15-23.

[11] Intensive Mixer. Available at: http://www.belloi.it/

[12] Durchlaufmischer. Available at: https://www.webac-gmbh.de/produkte/durchlaufmischer/

[13] DISA Mixers and SMC. Available at: https://www.disagroup.com/en-gb/products/sand-preparation-and-cooling/mixers-and-smc

[14] Soyuz CASTING information resource for foundry. Available at: http://lityo.com.ua/ oborudovanie/smeseprigotovitelnoe/ 